\title{
Completeness of Information Sources Used to Prepare Best Possible Medication Histories for Pediatric Patients
}

\author{
Deonne Dersch-Mills, Kimberly Hugel, and Martha Nystrom
}

\begin{abstract}
Background: Medication reconciliation can reduce medication errors and mortality. With limited availability of clinical pharmacists, it is important to determine the resources that will yield the most complete information about a patient's medication history.

Objective: To identify the most time-efficient sources of information about medication history for use by clinicians in a pediatric care setting.

Methods: In July and August 2009, newly admitted pediatric patients (under 18 years of age) were identified, and a best possible medication history (BPMH) was compiled from the admission history in each patient's chart, a provincial prescription database, a community pharmacy record, and an "informed interview". Each individual source of information was compared with the BPMH and given a completeness score based on 3 pieces of information about each medication (name, dose, and frequency).
\end{abstract}

Results: Data were collected for 99 pediatric patients. Of these, 76 (77\%) were taking at least one medication, and 49 (50\%) were taking at least one prescription medication. Among patients who were taking at least one medication, the informed interview, based on background information from other sources, resulted in the most comprehensive medication history, with a median completeness score of $100 \%$ (interquartile range [IQR] $90 \%$ to $100 \%$ ). The admission history had a median completeness score of $33 \%$ (IQR $4 \%$ to $56 \%$ ), with documentation of dose and frequency lacking most frequently. Information from community pharmacies had a median completeness score of $67 \%$ (IQR $42 \%$ to $87 \%$ ), but this source was available for only 24 of the 99 patients. The prescription database was the least complete source, with a median completeness score of $0 \%$ (IQR 0\% to 37\%).

Conclusion: An informed interview by a trained professional resulted in the most complete medication history. Admission histories represented the next most complete source. The data from this study indicated a need for education on the performance of medication reconciliation that would emphasize the use of all available background information, documentation of dose and frequency for each medication, and inclusion of both over-the-counter and herbal products.

Key words: pediatrics, medication reconciliation, adverse drug events, best possible medication history

\section{RÉSUMÉ}

Contexte : Le bilan comparatif des médicaments peut réduire les erreurs de médication et la mortalité. Étant donné la disponibilité limitée des pharmaciens cliniciens, il est important de déterminer les ressources qui permettront d'obtenir les renseignements les plus complets sur l'historique des médicaments d'un patient.

Objectif : Déterminer les sources d'information les plus complètes sur l'historique des médicaments devant être utilisées par les cliniciens dans un milieu de soins pédiatriques.

Méthodes : En juillet et août 2009, on a dressé une liste des enfants (de moins de 18 ans) nouvellement hospitalisés, puis le meilleur schéma thérapeutique possible (MSTP) a été établi à partir de l'anamnèse dans le dossier médical de chacun de ces patients, d'une base de données provinciale sur les ordonnances, du dossier de la pharmacie communautaire et d'une "entrevue éclairée ". Chaque source a été comparée avec le MSTP puis un score d'exhaustivité de l'information lui a été attribué en se fondant sur trois éléments d'information pour chaque médicament (nom, dose et fréquence d'administration).

Résultats : Les données ont été recueillies chez 99 enfants. De ce nombre, 76 (77\%) prenaient au moins un médicament et 49 (50\%) prenaient au moins un médicament d'ordonnance. Parmi les patients qui prenaient au moins un médicament, l'entrevue éclairée des renseignements préliminaires provenant d'autres sources a permis d'obtenir l'historique médicamenteux le plus complet, avec un score d'exhaustivité médian de $100 \%$ (écart interquartile [ÉIQ] de $90 \%$ à 100 $\%$ ). L'anamnèse a obtenu un score d'exhaustivité médian de $33 \%$ (ÉIQ de $4 \%$ à $56 \%$ ), les omissions les plus courantes étant la dose et la fréquence d'administration. Les dossiers des pharmacies communautaires ont obtenu un score d'exhaustivité médian de $67 \%$ (ÉIQ de $42 \%$ à 87 $\%$ ), mais cette source n'était disponible que pour 24 des 99 patients. La base de données sur les ordonnances était la source la moins complète, avec un score d'exhaustivité médian de $0 \%$ (ÉIQ de $0 \%$ à $37 \%$ ).

Conclusion : Une entrevue éclairée menée par un professionnel formé a permis d'obtenir l'historique des médicaments le plus complet. L'anamnèse constituait la deuxième source la plus complète. Les données de cette étude ont montré le besoin d'une formation sur l'éxécution du bilan comparatif des médicaments qui soulignerait le recours à tous les renseignements préliminaires disponibles, la consignation de la dose et de la fréquence d'administration de chaque médicament et l'inclusion des médicaments en vente libre et des produits à base de plantes médicinales. Mots clés : pédiatrie, bilan comparatif des médicaments, événements 
indésirables liés aux médicaments, meilleur schéma thérapeutique possible

\section{INTRODUCTION}

$\mathrm{M}$ any organizations that focus on medication safety and quality improvement in health care support medication reconciliation as a method of reducing medication-related errors at points of transition in care. One of the national patient safety goals issued in 2011 by the Joint Commission was "accurately and completely reconciling medications across the continuum of care". ${ }^{1}$ The standards of Accreditation Canada state that an organization should "reconcile clients' medications at admission and discharge, transfer or end of service". ${ }^{2}$ Indeed, medication reconciliation is considered the standard of practice for clinical hospital pharmacists. The American Society of Health-System Pharmacists ${ }^{3}$ and the Canadian Society of Hospital Pharmacists (CSHP $)^{4}$ both identify medication reconciliation as objective 1.1 within their respective practice excellence initiatives.

Medication reconciliation has been studied extensively in adult populations, where it has been shown to improve patient safety. ${ }^{5-14}$ Medication reconciliation can be expected to improve patient safety in pediatric populations as well, given that younger patients have a greater baseline risk of adverse drug events. ${ }^{15}$ One study of medication reconciliation in a pediatric population identified 2 discrepancies per patient. ${ }^{16}$ Another recent study estimated that close to $30 \%$ of discrepancies identified in this age group had the potential to cause moderate to severe discomfort or clinical deterioration. ${ }^{17}$ In a study begun in 2005, the Pediatric Medication Reconciliation Collaborative determined that the rates of undocumented and unintentional discrepancies were 0.43 and 0.58 per patient, respectively, at baseline. ${ }^{18}$ During the study period of active medication reconciliation, these rates decreased to 0.24 and 0.28 per patient, respectively. ${ }^{18}$ These preliminary results confirmed that there is great potential for these patients to benefit from medication reconciliation and further indicated that pediatric patients are at high risk of adverse drug events related to medication discrepancies at transition points.

The process of medication reconciliation has 2 main components. The first is the creation of a best possible medication history (BPMH), and the second involves comparing the BPMH with admission orders, identifying discrepancies, and then "reconciling" the discrepancies with the medical team. Although medication reconciliation is a well-established safety initiative, questions remain about how best to implement the process. One issue relates to the sources to be consulted in preparing the BPMH. Potential sources include the patient's chart, a provincial prescription database, information from a community pharmacy, records from outpatient clinics, medication administration records (MARs) from previous hospital admissions, and an interview with the patient or a caregiver. Each source has advantages and disadvantages, and none can stand alone as a complete and accurate source. To maximize the number of patients for whom a BPMH can be prepared at the time of admission, an accurate medication history must be obtained in a timely manner. Identification of the most comprehensive sources of information relevant to the medication history is integral to a multidisciplinary approach to medication reconciliation, allowing the process to be completed in a time-efficient manner.

Although pharmacist-led medication reconciliation has been beneficial in both adult and pediatric populations, ${ }^{8,10,12-14,16,19}$ inconsistent availability of clinical pharmacists may limit the ability to perform this task consistently. To support a multidisciplinary approach to medication reconciliation, this study was undertaken to identify the most comprehensive and timeefficient sources of medication history information for use by clinicians. ${ }^{20}$ Specifically, the completeness of various information sources used in the BPMH process was examined, in terms of drug name, dose, and frequency of administration. Such information will be useful in developing standard procedures for all disciplines to use during medication reconciliation.

\section{METHODS}

\section{Study Design}

This observational study was based on information gathered in the preparation of BPMHs in a convenience sample of 99 pediatric patients at the Alberta Children's Hospital during July and August 2009. The hospital's Child Health Scientific Review Committee and the University of Calgary's Conjoint Health Research Ethics Board approved the study protocol but deemed individual consent to be unnecessary, as preparation of a BPMH is a routine aspect of patient care.

\section{Study Population}

Newly admitted patients were identified by checking the local patient care information system and reviewing lists maintained by the general pediatrics team. Patients were eligible if they were under 18 years of age and had been admitted to a general pediatrics unit.

Patients were excluded if they had been admitted more than $48 \mathrm{~h}$ before the time when they were identified as potentially eligible or if they had been admitted to one or more other 
units before admission to a general pediatric unit (e.g., had been transferred from a pediatric or neonatal intensive care units).

\section{Interventions}

A student pharmacist (K.H.) identified eligible patients within $48 \mathrm{~h}$ after admission. A BPMH was then prepared from the following sources:

- review of physician's admission history and the medication list in the patient's chart

- review of preceding 6 months of prescription activity, as recorded in a provincial prescription database (Alberta Netcare)

- contact with the patient's community pharmacy, if the patient used the same pharmacy regularly

- review of other resources on a patient-specific basis (e.g., MARs from previous admissions to hospital or prescription vials).

- interview of the patient or a caregiver about medications being taken at home

Although clinical pharmacists commonly reviewed a patient's medications at the time of admission using at least one of the sources listed above, it was not usual practice to use all of these resources for every patient.

The initial admission history, as documented by the admitting team, was considered a "basic patient interview". The second interview, performed by the student pharmacist, was considered an "informed interview", as information from the other sources listed above was used as background for the interview (e.g., patients were asked to verify background data, or these data were used to trigger the caregiver's recall). The informed interview also included specific questions about overthe-counter products, vitamins, and herbal or complementary medicines. Finally, the student pharmacist used a review-ofsystems approach in asking the patient about medications being taken.

Information from all of these sources was compiled to create the BPMH, and discrepancies were brought to the attention of the clinical pharmacist on the relevant team; the clinical pharmacist reconciled these issues with the medical team. The BPMH, any discrepancies, and their resolution were documented in the patient's chart.

Informed interviews were not conducted if there was no caregiver or if the student was unable to speak to the patient or caregiver before discharge. For those patients, a completeness score of 0 was assigned for the informed interview to reflect the limitations of actual practice (e.g., time constraints or lack of caregiver availability), and the BPMH was compiled using all other available sources.

If the patient had no regular community pharmacy, either because he or she had had no prescriptions filled or because multiple pharmacies had been used, no completeness score was assigned for the patient's community pharmacy, and the BPMH was compiled using all other available sources.

\section{Data Analysis}

The BPMH was deemed to be $100 \%$ complete and was used as the standard against which every other information source was compared. Each of these sources was given a "completeness score" (expressed as a percentage of the information in the BPMH). The name of the medication, the dose (amount per dose), and the frequency of dosing were each given 1 point in calculating completeness. For example, if a medication was listed in the admission history with the correct name and dose but with a frequency different from that determined by the BPMH (based on all information sources), the completeness score assigned for the admission history was $66 \%$.

If no discernible "dose" was available for a medication (e.g., in the case of multivitamins or herbal products containing many different components), the dose was recorded as "1 dosage form" (e.g., tablet or drop).

The data were analyzed for the entire population and by subgroups based on the number of medications that each patient was taking. The subgroup analysis was intended to reduce bias (skewing) caused by the high number of completeness scores with a value of $100 \%$ for patients who were taking no medications. Analyses were performed for all medications and for prescription medications only. Post hoc analyses of the data based only on the medication name (omitting dose and frequency) were also performed.

Descriptive statistics were calculated with Microsoft Excel 2007 software. For each subgroup, median scores and interquartile ranges were calculated because the data were not normally distributed.

\section{RESULTS}

Data were collected for a total of 99 patients. For 16 of these patients, an informed interview could not be conducted, and a completeness score of 0 was assigned for this information source. For 24 of the patients, information could be obtained from a community pharmacy, but such information was not available for the remaining 75 patients, either because they had had no prescriptions filled or because they had obtained medications from multiple pharmacies. For these patients, no completeness score was assigned for this information source.

Of the 99 patients, $76(77 \%)$ reported taking at least 1 medication on a regular basis before admission, and 49 (50\%) reported taking at least 1 prescription medication on a regular basis before admission. For the subgroup analyses, 23 patients were taking no medications, 45 were taking 1 to 3 medications, and 31 were taking 4 or more medications.

The informed interview was the most complete source of information about medications, followed by community pharmacy records, the admission history, and finally the provincial prescription database (Table 1). The latter 2 categories had a broad range of scores (Table 1). When only prescription medications were considered, the overall scores tended to be higher (Table 1). 
After data collection began, it was noted that dose and frequency were the most common components missing from the sources. In a post hoc analysis of completeness scores based on the medication name alone, all of the sources scored higher than was the case in the main analysis (Table 2). Again, most of the sources had a broad range of completeness scores.

\section{DISCUSSION}

Unlike adult inpatients, many pediatric inpatients do not take medications regularly. For example, in the current study, $23 \%$ of the patients took no medications at all, and half took no prescription medications. An informed interview, completed

Table 1. Completeness Scores for Information Sources Based on Name, Dose, and Frequency of Medications Taken before Admission

Source; Median Completeness Score,\% (IQR)

\begin{tabular}{|c|c|c|c|c|c|c|c|c|}
\hline \multirow{2}{*}{$\begin{array}{l}\text { No. of Medications } \\
\text { Prescription and } \\
\text { nonprescription medications }\end{array}$} & \multicolumn{2}{|c|}{ Admission History } & \multicolumn{2}{|c|}{ Prescription Database } & \multicolumn{2}{|c|}{ Community Pharmacy* } & \multicolumn{2}{|c|}{ Informed Interviewt } \\
\hline & & & & & & & & \\
\hline All patients $(n=99)$ & 51 & $(23-100)$ & 40 & $(0-100)$ & 64 & $(42-87)$ & 100 & $(88-100)$ \\
\hline No medications ( $n=23$ ) & 100 & $(100-100)$ & 100 & $(100-100)$ & & NA & 100 & $(100-100)$ \\
\hline $1-3$ medications $(n=45)$ & 33 & $(0-50)$ & 0 & $(0-22)$ & 83 & $(53-100)$ & 100 & $(89-100)$ \\
\hline$\geq 4$ medications $(n=31)$ & 40 & $(25-63)$ & 33 & $(0-36)$ & 61 & $(42-79)$ & 100 & $(90-100)$ \\
\hline At least 1 medication $(n=76)$ & 33 & $(4-56)$ & 0 & $(0-37)$ & 67 & $(42-87)$ & 100 & $(90-100)$ \\
\hline \multicolumn{9}{|l|}{ Prescription medications only } \\
\hline All patients $(n=99)$ & 100 & $(58-100)$ & 100 & $(50-100)$ & 85 & $(63-100)$ & 100 & $(100-100)$ \\
\hline No medications $(n=50)$ & 100 & $(100-100)$ & 100 & $(100-100)$ & & NA & 100 & $(100-100)$ \\
\hline $1-3$ medications $(n=37)$ & 50 & $(33-83)$ & 50 & $(0-100)$ & 78 & $(47-100)$ & 100 & $(100-100)$ \\
\hline$\geq 4$ medications $(n=12)$ & 60 & $(55-81)$ & 46 & $(11-61)$ & 92 & $(73-97)$ & 96 & $(75-100)$ \\
\hline At least 1 medication $(n=49)$ & 57 & $(33-80)$ & 50 & $(0-100)$ & 78 & $(58-100)$ & 100 & $(94-100)$ \\
\hline
\end{tabular}

$\mathrm{IQR}=$ interquartile range, NA = not applicable.

*Overall, data from a community pharmacy were available for only 24 of the 99 patients. For patients without data from a community pharmacy, no score was recorded for this information source.

tInformed interviews could not be conducted for 16 of the 99 patients. For these patients, the completeness score for this information source was recorded as $0 \%$.

\section{Table 2. Completeness Scores for Information Sources Based Solely on Names of Medications Taken before Admission}

Source; Median Completeness Score,\% (IQR)

No. of Medications

Admission History

Prescription Database

Community Pharmacy* Informed Interview†

\section{Prescription and nonprescription medications}

\begin{tabular}{|c|c|c|c|c|c|c|c|c|}
\hline All patients $(n=99)$ & 75 & $(33-100)$ & 50 & $(0-100)$ & 69 & $(51-100)$ & 100 & $(100-100)$ \\
\hline No medications ( $n=23$ ) & 100 & $(100-100)$ & 100 & $(100-100)$ & & NA & 100 & $(100-100)$ \\
\hline $1-3$ medications $(n=45)$ & 50 & $(0-100)$ & 0 & $(0-50)$ & 100 & $(92-100)$ & 100 & $(100-100)$ \\
\hline$\geq 4$ medications $(n=31)$ & 54 & $(33-75)$ & 33 & $(9-51)$ & 59 & $(50-74)$ & 100 & $(100-100)$ \\
\hline At least 1 medication $(n=76)$ & 50 & $(11-83)$ & 21 & $(0-50)$ & 69 & $(51-100)$ & 100 & $(100-100)$ \\
\hline \multicolumn{9}{|l|}{ Prescription medications only } \\
\hline All patients $(n=99)$ & 100 & $(100-100)$ & 100 & $(90-100)$ & 100 & $(85-100)$ & 100 & $(100-100)$ \\
\hline No medications $(n=50)$ & 100 & $(100-100)$ & 100 & $(100-100)$ & & NA & 100 & $(100-100)$ \\
\hline $1-3$ medications $(n=37)$ & 100 & $(67-100)$ & 100 & $(0-100)$ & 100 & $(100-100)$ & 100 & $(100-100)$ \\
\hline$\geq 4$ medications $(n=12)$ & 75 & $(61-98)$ & 50 & $(3-79)$ & 100 & $(79-100)$ & 100 & $(100-100)$ \\
\hline At least 1 medication $(n=49)$ & 100 & $(61-100)$ & 100 & $(0-100)$ & 100 & $(80-100)$ & 100 & $(100-100)$ \\
\hline
\end{tabular}

$\mathrm{IQR}=$ interquartile range, $\mathrm{NA}=$ not applicable.

*Overall, data from a community pharmacy were available for only 24 of the 99 patients. For patients without data from a community pharmacy, no score was recorded for this information source.

tInformed interviews could not be conducted for 16 of the 99 patients. For these patients, the completeness score for this nformation source was recorded as $0 \%$. 
after other sources had been consulted, was consistently more complete than any single source in isolation. It can be inferred that background knowledge allowed the informed interviewer to prompt patients or caregivers about medications noted in previously consulted resources (as well as medications typically used for each patient's diagnosed disease or condition), their doses, and how often they were taken. The informed interviewer consistently included over-the-counter products, herbal products, and vitamins, in addition to prescription medications, in her questioning and documented all medication-related components mentioned by the patient or caregiver (i.e., name, dose, and/or frequency).

For most of the patients (86 or $87 \%$ ), the medication history was documented as part of the admission history. However, the median completeness score for admission histories for patients taking at least 1 medication was $33 \%$, with a wide interquartile range ( $4 \%$ to $56 \%$ ), which may indicate inconsistencies in the completeness of information obtained from basic admission interviews. Admission histories were often incomplete because the dose and/or frequency of medications was missing; as such, the median completeness score improved (from 33\% to 50\%) when only the medication name was considered. It is likely that discrepancies in the admission histories were due to a lack of documentation (rather than a lack of determining the actual dosage on admission), because dosing discrepancies were not noted in admission orders for medications. Nonetheless, documentation of all information about medications remains an important component of obtaining a medication history, as it ensures that the correct dose and frequency of medications are ordered in hospital and across the continuum of care. . $9,21-24^{2}$

Consultation with a regular community pharmacy was the second most complete source of information, but use of this source was limited by the fact that many patients did not have a pharmacy that they used consistently and exclusively. It may be most useful to contact community pharmacies for patients with more complex medication regimens, such as those who are taking more than 3 medications or those who require titration of dosing schedules or compounded prescriptions.

The provincial prescription database was the least complete source for all subgroups of patients. It was limited by system downtimes and pharmacies that do not upload all prescription data; in addition, this source cannot reflect dosage adjustments discussed verbally by the physician and the patient. This finding was consistent with those of Kalb and others, ${ }^{25}$ who reported that $60 \%$ of patient medication histories derived from a provincial prescription database were incorrect. Although such databases have the potential to improve patient care, they will have limited benefit and carry the potential for harm if their use is not implemented on a widespread and consistent basis by all involved. The validity of this type of prescription activity profile can be increased through confirmation with other sources, as well as through questioning about use of products that are not regularly recorded by pharmacies.
The post hoc analysis of data based on medication name only was performed because having at least the medication name has some, albeit limited, benefits. The medication name can act as a prompt for further investigation, allowing the health care provider to avoid an error of complete omission and preventing the disease or symptoms from going untreated. As well, a basic assessment of adverse drug reactions and interaction checks can be performed on the basis of medication names alone. However, it should be emphasized that having only the name is insufficient for complete care, as errors in dose and frequency have significant potential to be harmful. The analysis based on medication names also revealed the weaknesses of the various sources in terms of documentation of dose and frequency. This information can be used to tailor future education of health care professionals about the components that are important for the completeness of medication histories.

Over-the-counter and herbal products were frequently missed by all sources except the informed interview. As such, the completeness scores increased when only prescription medications were considered (i.e., data for patients taking at least 1 medication): for admission histories, the completeness score increased from $33 \%$ to $57 \%$, for the prescription database, the score increased from $0 \%$ to $50 \%$, and for community pharmacies, the score increased from $67 \%$ to $78 \%$. Documentation of use of over-the-counter and herbal products is important to gain a more comprehensive clinical picture of the patient and his or her overall health. Although these products may be viewed as "natural" or harmless, they can cause symptoms, may interact with other medications, or may cause worsening or emergence of disease states.

This study had limitations. A large number of patients were taking no medications at all, and the overall results were therefore skewed toward completeness scores of $100 \%$. The use of subgroups reduced the impact of this effect. The severity and potential impact of the recorded discrepancies was not considered; however, the benefit of medication reconciliation has been well documented in adults. ${ }^{5-15}$ In retrospect, recording the amount of time required to access the available sources of information and to perform the informed interview, in addition to determining the completeness and accuracy of these sources, would have been useful in determining the efficiency of each resource. Finally, the system of scoring completeness used in this study has not been validated. However, this scoring system is consistent with the definition of completeness (drug, dose, and frequency) used to assess the completeness of medication histories in previous studies of medication reconciliation. ${ }^{8,12,22}$

The results of this study indicate that an informed interview is, by far, the most complete source of information for a BPMH. Ideally, all available resources would be used as background for an informed interview, to ensure the most comprehensive medication history for each patient. However, if time constraints prevent the use of multiple resources, the most time-efficient resources should be used. An informed interview 
that uses information from the admission history as background and that includes questioning about prescription, overthe-counter, and herbal medications used on a regular basis, as well as doses and frequencies of these medications, will yield a more complete history than admission histories alone, and will do so in a time-efficient manner. For patients with more complex medication regimens and those who use a single pharmacy for the majority of their medication needs, contacting the community pharmacy may be beneficial, and the time spent making such contact may be warranted. If time permits, review of a prescription database can be time-efficient and potentially beneficial. However, reliance on the database as the only source of information is not currently recommended because of the lack of accuracy shown by this and other studies. ${ }^{25}$

\section{CONCLUSIONS}

A BPMH requires an informed interview with the patient or caregiver, conducted by trained personnel. Education of health care professionals about the sources available for completion of a medication history and the importance of documenting all components pertaining to each medication is necessary. Such education would improve the accuracy of medication histories and support the performance of medication reconciliation by all health care professionals.

\section{References}

1. Accreditation program: hospitals. National patient safety goals. Effective January 1, 2011. Oakbrook Terrace (IL): The Joint Commission; 2010 [cited 2011 Jan 9]. Available from: www.jointcommission.org/assets/ 1/6/2011_NPSGs_HAP.pdf

2. Required organizational practices. Ottawa (ON): Accreditation Canada; 2010 Apr [cited 2010 Jan 9]. Available from: www.accreditation.ca/ uploadedFiles/ROP-Handbook-April-2010-EN.pdf

3. ASHP 2015. Health-system pharmacy initiative. Bethesda (MD): American Society of Health-System Pharmacists; 2005 [updated 2008; cited 2009 Apr 8]. Available from: www.ashp.org/s_ashp/docs/files/2015_ Goals_Objectives_0508.pdf

4. CSHP 2015: targeting excellence in pharmacy practice. Ottawa (ON): Canadian Society of Hospital Pharmacists; 2007 [cited 2009 Apr 8]. Available from: www.cshp.ca/programs/cshp2015/index_e.asp

5. Tam VC, Knowles SR, Cornish PL, Fine N, Marchesano R, Ethchells EE. Frequency, type and clinical importance of medication history errors at admission to hospital: a systematic review. CMAJ 2005;173(5):510-515.

6. Lau HS, Florax C, Porsius AJ, De Boer A. The completeness of medication histories in hospital medical records of patients admitted to general internal medicine wards. Br J Clin Pharmacol 2000;49(6):597-603.

7. Cornish PL, Knowles SR, Marchesano R, Tam V, Shadowitz S, Juurlink $\mathrm{DN}$, et al. Unintended medication discrepancies at the time of hospital admission. Arch Intern Med 2005;165(4):424-429.

8. Lizer MH, Brackbill ML. Medication history reconciliation by pharmacists in an inpatient behavioral health unit. Am J Health Syst Pharm 2007;64(10):1087-1091.

9. Gleason KM, Groszek JM, Sullivan C, Rooney D, Barnard C, Noskin GA. Reconciliation of discrepancies in medication histories and admission orders of newly hospitalized patients. Am J Health Syst Pharm 2004;61(16):1689-1695

10. Lubowski TJ, Cronin LM, Pavelka RW, Briscoe-Dwyer LA, Briceland LL, Hamilton RA. Effectiveness of a medication reconciliation project conducted by PharmD students. Am J Pharm Educ 2007;71(5):1-7.
11. Pippins JR, Gandhi TK, Hamann C, Ndumele CD, Labonville SA, Diedrichsen EK, et al. Classifying and predicting errors of inpatient medication reconciliation. J Gen Intern Med 2008;23(9):1414-1422.

12. Kwan Y, Fernandes OA, Nagge JJ, Wong GG, Huh JH, Hurn DA, et al. Pharmacist medication assessments in a surgical preadmission clinic. Arch Intern Med 2007;167(10):1034-1040.

13. Bond CA, Raehl CL. Clinical pharmacy services, pharmacy staffing, and hospital mortality rates. Pharmacotherapy 2007;27(4):481-493.

14. Kaboli PJ, Hoth AB, McClimon BJ, Schnipper JL. Clinical pharmacists and inpatient medical care: a systematic review. Arch Intern Med 2006;166(9):955-964.

15. Kaushal R, Bates DW, Landrigan C, McKenna KJ, Clapp MD, Federico $\mathrm{F}$, et al. Medication errors and adverse drug events in pediatric inpatients. JAMA 2001;285(16):2114-2120.

16. Lasak-Temme L, Englert L, Scarpace S. Pharmacist initiated medication reconciliation in a children's hospital. J Pediatr Pharmacol Ther 2008; 13(3):193-194.

17. Coffey M, Mack L, Streitenberger K, Bishara T, De Faveri L, Matlow A. Prevalence and clinical significance of medication discrepancies at pediatric hospital admission. Acad Pediatr 2009;9(5):360-365.e1.

18. Pediatric medication reconciliation collaborative. Key strategies and essential success elements. The 3-year journey. Ottawa (ON): Canadian Association of Pediatric Health Centres; 2009 Sep 29[cited 2010 Jan 12]. Available from: www.caphc.org/documents_programs/patient_safety/ pmrc_final.pdf

19. Camire E, Moyen E, Stelfox HT. Medication errors in acute care: risk factors, prevention and disclosure. CMAJ 2009;180(9):936-941.

20. Coleman EA, Smith JD, Raha D, Min SJ. Posthospital medication discrepancies: prevalence and contributing factors. Arch Intern Med 2005; 165(16):1842-1847.

21. Manley HJ, Drayer DK, McClaran M, Bender W, Muther RS. Drug record discrepancies in an outpatient electronic medical record: frequency, type, and potential impact on patient care at a hemodialysis center. Pharmacotherapy 2003;23(2):231-239.

22. Bedell SE, Jabbour S, Goldberg R, Glaser H, Gobble S, Young-Xu Y, et al. Discrepancies in the use of medications: their extent and predictors in an outpatient practice. Arch Intern Med 2000;160(14):2129-2134.

23. Beers MH, Munekata M, Storrie M. The accuracy of medication histories in the hospital medical records of elderly persons. J Am Geriatr Soc 1990;38(11):1183-1187.

24. Price D, Cooke J, Singleton S, Feely M. Doctors' unawareness of the drugs their patients are taking: a major cause of over-prescribing? Br Med J (Clin Res Ed) 1986;292(6513):99-100.

25. Kalb K, Shalansky S, Legal M, Khan N, Ma I, Hunte G. Unintended discrepancies associated with reliance on prescription databases for medication reconciliation on admission to a general medical ward. Can J Hosp Pharm 2009;62(4):284-289.

Deonne Dersch-Mills, BScPharm, ACPR, PharmD, is the Pharmacy Clinical Practice Leader, Pediatrics and Neonatology, Alberta Health Services-South, Calgary, Alberta.

Kimberly Hugel, BSc, BScPharm, is the Pharmacy Manager, Paragon Pharmacy, Strathmore, Alberta. She is also a casual pharmacist at Alberta Children's Hospital, Calgary, Alberta.

Martha Nystrom, BSP, MBA, is Patient Care Manager - Pharmacy, Alberta Children's Hospital, Alberta Health Services, Calgary, Alberta.

\section{Address correspondence to:}

Dr Deonne Dersch-Mills

Inpatient Pharmacy Department

Alberta Children's Hospital

2888 Shaganappi Trail NW

Calgary AB T3B 6A8

e-mail: deonne.dersch-mills@albertahealthservices.ca 